\title{
SEGATA, Jean; RIFIOTIS, Theophilos (orgs.). 2016. Politicas etnográficas no campo da cibercultura. Brasília, ABA Publicações; Joinville, Editora Letradágua. 208 pp.
}

MADSON J ALBINO RAFAEL

Os textos que constituem a obra Políticas etnográficas no campo da cibercultura buscam em seu conjunto, apresentar um balanço da pesquisa etnográfica nos estudos da cibercultura. De modo específico, traz a tona interrogações por parte do GrupCiber do Programa de Pós- Graduação em Antropologia Social da Universidade de Santa, um grupo de pesquisa no campo da cibercultura no Brasil, sendo pioneiro nesses estudos. Desde 1996 o grupo busca realizar um debate acerca das práticas de sociabilidade no campo da cibercultura, através da etnografia, visando os interesses subjacentes ao aos mais diversos temas, tais como: realidade virtual, inteligência artificial e comunicação mediada por computador.

O livro/e-book faz parte das concretizações do GrupCiber com o objetivo de reunir alguns dos textos que exprimem o modo de pensar e fazer etnografia da cibercultura pertinentes ao grupo, e seu anteparo teórico em autores como Arturo Escobar e Bruno Latour. O livro ora resenhado também é enriquecido com o debate dessas ideias para o estabelecimento de noções norteadoras da pesquisa antropológica da cibercultura em autores e membros do grupo como Jean Segata e Theophilos Rifiotis. Em sequência são apresentadas e discutidas algumas questões da prática da pesquisa etnográfica no campo da cibercultura através dos relatos de pesquisa de Dalila Petry e Maria Elisa Máximo.

A coletânea é iniciada com um artigo de Arturo Escobar, "Bem-vindos à cyberia: notas para uma antropologia da cibercultura", texto publicado em 1994, portanto, no início da popularização do computador e da incipiente internet como meio de comunicação. O artigo foi traduzido por Tatiana Dassi, Jean Segata e Theophilos Rifiotis, a partir do original "Welcome to Cyberia: notes on the Anthropology of Cyberculture”, publicado no Current Anthropolgy, v. 35, n. 3, 1994, p. 211-231.

Segundo Escobar, a sua investigação parte da crença de que qualquer tecnologia representa uma invenção cultural, no sentido de que "ela produz um mundo" (p.22). O autor trata da modernidade e das tecnologias no escopo das ciências sociais, em que estas tratam aquelas dentro da chave do determinismo evolucionista. Arturo data a década de 1960 como um marco da mudança dessa perspectiva com a instituição de projetos de ensino e pesquisa em que são demarcadas as implicações da ciência e da tecnologia como formas dominantes de conhecimento de práticas da cultura moderna. Em oposição a 
essa visão determinista da ciência e da tecnologia coloca-se a proposta metodológica do construtivismo social, que busca estabelecer a contingência e a flexibilidade como essência da mudança tecnológica. Para Escobar, a "teoria-ator-rede" (TAR) de Micchel Callon e Bruno Latour é o exemplo das mudanças nos estudos de ciência e tecnologia, pois estes autores visam compreender um novo tipo de agência, de estratégias com as quais os atores - humanos e não humanos - se debatem diante de problemas e na busca por soluções adequadas.

Escobar elenca um conjunto de questões que podem guiar a investigação antropológica no campo da cibercultura, tais como: quais os discursos e práticas são criados por e em torno dos computadores e da biotecnologia? Como estudar etnograficamente essas práticas e domínios em diferentes espaços sociais, regionais e étnicos? Qual o pano de fundo, ou mais especificamente, quais práticas modernas, moldam a atual compreensão, caracterização e maneiras de nos relacionarmos com a tecnologia? E por fim, qual é a economia política da cibercultura e quais novas articulações locais com formas de capital global, baseados em novas tecnologias, estão aparecendo?

Essas questões se entrelaçam nas formulações teóricas do projeto antropológico sobre a relação entre cultura e tecnologia, entre humano e máquina imbricados numa "antropologia do ciborgue", na medida em que a realidade humana é produto tanto de máquinas como da atividade humana. Essas formas de ver modificam ou "implodem" categorias modernas - dicotomias - como o natural, o orgânico, o técnico e o textual (Haraway, 1991; Rabinow 1991; Foucault, 1975). O uso de novas tecnologias propicia a produção de subjetividades, as questões de memória, pertença e comunidade (Turkle, 1984; Laurel, 1990; Barry, 1992; Harness, Goodwin, 1992).

O texto de Bruno Latour, "Faturas / Fraturas: da noção de rede à noção de vínculo", traduzido por Theophilos Rifiotis, Jean Segata e Dalila Floriani Petry, é nesta coletânea o ponto central, principalmente em relação às apropriações das perspectivas teórico-metodológicas adotadas pelo GrupCiber. Latour parte de uma explicação de uma tirinha da Mafalda (Quino, 1986) em que ela surpreende seu pai fumando e o questiona com seu humor peculiar se é ele quem fuma ou se ele é que estaria sendo fumado pelo cigarro. Assim, a relação sujeito-objeto vai sendo desmontada para dar início a uma teoria contracionista da ideia de "faitiches", na compreensão do "faz fazer" (p.69).

Sobre a questão de causa e efeito tão cara às explicações modernas, conforme diz Latour: os faitiches nos autorizam a não levar tão a sério as formas sempre conjugadas dos objetos e dos sujeitos. Outra indagação do autor é sobre os vínculos, onde ele afirma que o mais importante no momento não é mais a questão de sabermos se somos livres ou vinculados, mas se somos bem ou mal vinculados, verificando sim, a qualidade desses laços.

Segundo Latour é preciso questionar mais sobre a natureza do que nos comanda do que de tratar de uma reconciliação entre indivíduo e sociedade ou ator e sistema. Nesse sentido, a noção de vínculo faz renunciar à noção de sociedade e de ator, após reatar os fios da ação. De modo bastante claro, Latour afirma que "para compreender a movimentação dos sujeitos, suas emoções, suas paixões, é preciso, portanto, interessar-se sobre aquilo que os vincula e os movimenta" (p.81). Em suma: no processo de dar vez e voz aos vínculos se define uma sociologia das redes, conservando o efeito de sua distribuição como o de reforço da natureza e da fonte da ação. 
O artigo intitulado "Dos cibernautas às redes", de autoria de Jean Segata, aborda a inserção da antropologia na disputa em torno da discussão dos efeitos da "emergência de computadores e internet" (p.91). Nesse debate, as pesquisas do GrupCiber, ao menos incialmente, estão próximas do campo da comunicação, havendo posteriormente uma mudança em sua perspectiva, agora entendida como um espaço social de relação da cibercultura. Essa chave de leitura da cibercultura se confirma a partir da Teoria Ator-Rede de Bruno Latour, em que a rede passa a ser notada como uma rede sociotécnica. A antropologia da cibercultura afasta-se então das noções da netnografia, cujo debate gira em torno de questões sobre realidade e virtualidade, para dar lugar às pesquisas em torno de agentes humanos e não humanos.

Theophilos Rifiotis, em seu artigo, "Desafios contemporâneos para a Antropologia no ciberespaço: o lugar da técnica" discute acerca da técnica na perspectiva antropológica clássica, onde o autor critica as noções de "uso" "apropriação" e "representação" no campo da cibercultura. Rifiotis refere-se ao primeiro objeto técnico que é o próprio corpo, seguindo, assim, os apontamentos seminais de Marcel Mauss, formulada na perspectiva deste autor sobre o "fato social total".

Desse modo, Rifiotis, insiste na compreensão de que a antropologia não possui fronteiras, por exemplo, no tocante a pensar as comunidades "virtuais" do mesmo modo como se opera com as ditas sociedades "tradicionais". Este seria um equívoco na perspectiva do campo dos estudos da cibercultura. O autor vai mais além e provoca deslocamentos ao discutir sobre os termos "sociedade" e "cultura" baseado em M. Strathern (2006), para quem "nossas próprias metáforas remetem uma metafisica profundamente enraizada, com manifestações que emergem em todas as nossas análises”. Esse modo de pensar o social segue as considerações teóricas de B. Latour (2008), para quem a sociologia do social não é capaz de rastrear as novas associações dos atores, sejam eles humanos ou não humanos.

No artigo subsequente, "Etnografia no ciberespaço como "repovoamento" e explicação", Theophilos Rifiotis discute o lugar central que a etnografia sempre teve nos trabalhos do GrupCiber, assim oferece um leitura sobre os possíveis problemas enfrentados na pesquisa no ciberespaço. Os dados etnográficos, se não são mais tomados com base numa concepção do "realismo" ainda necessitam ser problematizados quanto à questão da tradução. Rifiotis (p. 135) recorre às afirmações de Goodman (1972), para reafirmar a ideia de que os fatos são feitos e revelam não “o modo como o mundo é”, mas sim "um modo como o mundo é" (destaque meu). Esta noção corrobora com a ideia de B. Latour, sobre os efeitos das narrativas e suas criações.

A partir da virada sociotécnica, o GrupCiber (Rifiotis demarca, para tal, o ano de 2008) busca focar seus trabalhos não nos atores humanos em ação na internet, mas evidenciar as conexões entre humanos e não humanos, buscando superar dicotomias arraigadas nas teorias clássicas. Isso é demonstrado na ideia de repovoamento da cibercultura, evitando separações entre mundo técnico e mundo humano, reafirmado com B. Latour sobre os objetos não serem simples telas ou retroprojetores da nossa vida social. Nesse contexto, ressalta-se a importância da noção de actante - ideia retirada por Latour da semiótica de Greimas (1976) - para comportar todos os elementos que estão envolvidos na tessitura do social. 
O penúltimo artigo da coletânea, "Revisitando o Floresta Digital: notas sobre o esforço de uma descrição sociotécnica”, de autoria de Dalila Floriani Petry, traz a baila um estudo significativo de uma politica pública de inclusão digital no Estado do Acre, denominada "Floresta Digital". A autora desenvolve sua pesquisa para o mestrado em consonância com as discussões empreendidas no GrupCiber, cujo objetivo central era produzir uma descrição sociotécnica, buscando evidenciar nesse processo os coletivos que são associados e os atores - humanos e não humanos - mobilizados para esse programa. A ideia da autora de revisitar a sua dissertação tem como proposta, refletir sobre as perspectivas teórico-metodológicas que a orientaram, como também, tratar das dificuldades da produção de um relato desse tipo (p. 155). Um ponto de destaque é o tratamento do que a autora chamou de controvérsias definidas como associações que modificam suas definições, sendo esse entendimento enriquecedor para perceber a complexidade da vida coletiva. Assim, os agenciamentos são tratados na perspectiva da Teoria Ator-Rede, visando perceber os rastros deixados por essas movimentações nas redes de mediações, que não estão dadas, mas se formam na relação / ação entre os atores. Vale ressaltar que nesse texto e no próximo de Maria Elisa Máximo, o debate de ideias e teorias realizadas pelo GrupCiber aparecem claramente ao leitor, deixando claro o modo como as autoras conseguiram se valer destes momentos para desenvolverem suas pesquisas. Há uma expressão de prática da pesquisa no campo da cibercultura que vale a pena ser vista por quem já se aventura nesse trabalho e digo mais, que para quem quer se iniciar, são pistas valiosas do desenrolar de pesquisas que podem ser tratadas como modelares.

Por fim, Maria Elisa Máximo, discute sobre as informações de saúde buscadas na internet, especificamente no site de busca Google, pelo chamado "paciente informado" ou "paciente expert". Seu artigo, intitulado de "O paciente informado: primeiras notas de um estudo etnográfico", parte da questão de como fazer etnografia numa perspectiva sociotécnica, considerando-se as agências humanas e não humanas. A busca dessa simetria está também baseada na teoria de B. Latour (1994). No desenrolar da pesquisa a autora se concentrou no acesso aos conteúdos específicos de saúde disponíveis na internet, com o objetivo de pensar os modos pelos quais estes estão imbricados nos processos de tratamento e acompanhamento de saúde das pessoas que os buscam.

A pesquisa buscou saber quem seria esse paciente, o modo como ele se informa, sobre os conteúdos, quais informações são privilegiadas e mais, qual a descrição de suas relações e suas interações com os sites e com as ferramentas de busca. Todas essas questões faziam parte de um roteiro pré-estabelecido para as entrevista. A forma com que Maria Elisa Máximo conduz sua pesquisa e o seu relato tem dois aspectos que valem ser ressaltados: primeiro, na questão da metodologia, o seu desenho fica claro e corresponde aos anseios de uma pesquisa no âmbito de uma rede sociotécnica. E, segundo, porque demonstra algo diretamente na relação médico- paciente, que passa a ser entendida não mais como uma relação entre dois, mas propriamente dita, entre três, considerando a internet como fazendo parte desta relação dotada, assim de mais simetria do que antes pudesse ser pensada.

Evidenciar e revisar criticamente as contribuições do GrupCiber, a partir de seus membros fundadores, tratando de temas que estiveram em voga nos últimos 20 anos, torna-se muito importante por expressar os desafios enfrentados por esse grupo pioneiro de pesquisadores que vivenciaram a passagem de um século para o outro repleto de inovações no campo da tecnologia e de suas implicações na vida 
humana. Este motivo já é o suficiente para fazer deste e-book uma leitura pertinente para os estudos etnográficos no campo da cibercultura. No entanto, não é demais afirmar a importância desses estudos organizados pelo GrupCiber ao longo desses anos em seus desdobramentos teórico-metodológicos, como também no tocante as mais diversas questões que surgem a cada momento, como afirmam Jean Segata e Theophilos Rifiotis na introdução, que "é preciso pensar uma agenda prática, política ou aplicada, para a disciplina, no campo da cibercultura" (p. 18). O esforço da obra em contextualizar/confrontar o referido debate ganha relevância a partir do amplo leque temático possível que é suscitado a todo o momento e abordado de forma multidisciplinar cumprindo seu objetivo enquanto expoente e desbravador das possibilidades e desafios que esses estudos requerem.

Madson José Albino Rafael é doutora em Sociologia pelo Programa de Pós-Graduação em Sociologia da UFPE.

RECEBIDO: $03 / 03 / 2017$

APROVADO: $20 / 07 / 2017$ 
270 CAMPOS v.18(1-2), 2017 